\title{
Optimal care of patients with non-small cell lung cancer reduces perioperative morbidity
}

\author{
Robert J. Cerfolio, MD, FACS, FCCP, ${ }^{\mathrm{a}}$ and Ayesha S. Bryant, MSPH, MD ${ }^{\mathrm{b}}$
}

Objective: The objective is to test the concept of "pay for performance" for patients with non-small cell lung cancer.

\begin{abstract}
Methods: We constructed 53 benchmark performance standards (10 labeled "critical") and prospectively assessed the effect of adherence to these standards on morbidity and mortality for patients undergoing resection of non-small cell lung cancer.
\end{abstract}

Results: Between January 1, 2007, and December 31, 2009, 778 patients with non-small cell lung cancer underwent thoracotomy by 1 surgeon. Ninety-seven percent of patients received all 26 of the "day of surgery" and "intraoperative" benchmarks, and those were the easiest to deliver. The 469 patients who had all 53 benchmarks delivered, compared with the 309 who did not, had a lower mortality $(2.0 \%$ vs $2.3 \%)$ and morbidity ( $16 \%$ vs $44 \% ; P<.001)$. The 693 patients who received all 10 "critical" benchmarks, compared with the 85 who did not, had a lower mortality $(1.9 \%$ vs $4.7 \%)$ and morbidity $(25 \%$ vs $41 \% ; P=.003)$. Low household income and fewer than 2 people in the household were predictors of overall morbidity on univariate analysis.

Conclusions: Most benchmarks, especially "day of surgery" and "intraoperative" ones, can be delivered in more than $97 \%$ of patients. The delivery of benchmarks reduces perioperative morbidity but not mortality. Socioeconomic factors are predictors of overall morbidity. Operative mortality is related to the "quality of the patient" and the "quality of the health care provider." (J Thorac Cardiovasc Surg 2011;141:22-33)

Earn CME credits at

$\mathrm{http} / / / \mathrm{cme}$.ctsnetjournals.org

In 2001, the Institute of Medicine recommended that health plans adopt a pay for performance concept. ${ }^{1,2}$ The theory was that if physicians were rewarded for the delivery of high-quality care instead of receiving payment based on the quantity of care, quality would improve and patient outcomes would improve. Although the concept is sound, the data supporting it are mixed. We are all aware of patients who receive outstanding care but have bad outcomes. In addition, several studies have shown little to no effect of the pay for performance system. ${ }^{3-5}$ One of these negative

From the Division of Cardio-Thoracic Surgery, Section of Thoracic Surgery ${ }^{\mathrm{a}}$ and Department of Surgery, ${ }^{\mathrm{b}}$ University of Alabama at Birmingham, Ala.

Disclosures: Robert J. Cerfolio: E plus health care, speaker; Ethicon, speaker/consultant, Neomend, consultant; Millicore, speaker/consultant, Medela, speaker/consultant, Closure/J\&J, consultant; OSI Pharm, speaker; Atrium, consultant/speaker; Oncotech, speaker; Covidien, speaker; Precision, consultant/speaker. Ayesha S Bryant has no financial disclosures to report.

Read at the 36th Annual Meeting of The Western Thoracic Surgical Association, Ojai, California, June 23-26, 2010.

Received for publication June 25, 2010; revisions received Sept 9, 2010; accepted for publication Sept 22, 2010; available ahead of print Nov 11, 2010.

Address for reprints: Robert J. Cerfolio, MD, Professor of Surgery, Chief of Thoracic Surgery, Division of Cardiothoracic Surgery, University of Alabama at Birmingham, 703 19th St S, ZRB 739, Birmingham, AL 35294 (E-mail: Robert. cerfolio@ccc.uab.edu).

$0022-5223 / \$ 36.00$

Copyright (c) 2011 by The American Association for Thoracic Surgery doi:10.1016/j.jtcvs.2010.09.013 studies tested the concept of cancer screening programs in Medicaid patients, the second was patient outcomes after myocardial infarction, and the third evaluated enhancing mammography in primary care. However, 3 other studies did show improve outcomes when pay for performance was adopted..$^{6-8}$ These studies concerned diabetes management, mammography, and the reduction of lipid levels. The concept has also been been studied in patients with non-small cell lung cancer (NSCLC), and although none of those or our benchmarks (or quality metrics) have been validated, we have all chosen similar ones. ${ }^{9,10}$ In this study we evaluated the "pay for performance" concept when applied to the surgical care of patients with NSCLC who undergo thoracotomy and pulmonary resection. We identified benchmarks and evaluated our ability to deliver them. We divided the benchmarks into 4 categories that we believed were important to the care of patients with NSCLC: preoperative benchmarks, day of surgery, intraoperative, and postoperative benchmarks The goal of this study was to assess our ability to deliver these benchmarks and then to analyze how the delivery affected patient outcomes, specifically operative mortality, major morbidity, and overall morbidity.

\section{METHODS}

In December 2006 we decided to try to further improve the overall care that we provided for patients with NSCLC. The goal was to provide the absolute best care possible, or what we labeled "optimal care," for patients who called our office and then underwent rib-sparing, intercostal nerve-sparing thoracotomy. ${ }^{11-13}$ We assessed all aspects of our care that we could. We assessed our ability to get patients into the preoperative clinic quickly, to 


\section{Abbreviations and Acronyms \\ ICU = intensive care unit \\ NSCLC $=$ non-small cell lung cancer \\ PQRI = Physician's Quality Reporting Initiative \\ STS $=$ The Society of Thoracic Surgeons \\ $\mathrm{UAB}=$ University of Alabama at Birmingham \\ VATS $=$ video-assisted thoracic surgery}

receive all of the necessary tests, and then get them through surgery. Preoperative staging tests were performed as previously described. ${ }^{14,15}$

We identified all of the aspects of patient care that seemed important and evaluated those along with relevant ones previously sited, such as in the Physician's Quality Reporting Initiative (PQRI). ${ }^{16}$ We labeled these "benchmarks." The 53 benchmarks selected for this study are listed in Table 1. Our ability to deliver each benchmark for each patient was recorded. We then evaluated the benchmark's relationship to outcome. Benchmarks were subclassified in various ways: (1) the time that the benchmark was delivered during the patient's care: "preoperatively," "day of surgery," "intraoperatively," or postoperatively"; (2) "critical" (defined as specific aspects of care that were vital to ensuring a good outcome) and "noncritical" (all others); (3) impact factor (a subjective score given to each benchmark from 1-5, with 1 being least critical and 5 being most critical to patient outcomes). All critical benchmarks received an impact factor of 5. A fourth category of benchmarks was based on the aspect of care that they addressed. They were called either "quality of care" benchmarks or "patient satisfaction" benchmarks.

In addition, we created a score for each patient that we called a weighted score. The weighted score was calculated by multiplying the quality of care benchmarks only by the impact factor and then adding all of the scores for each benchmark for 1 patient. "Patient and family" satisfaction benchmarks were eliminated from this calculation. In addition, we eliminated benchmarks that all patients were not eligible to receive. For example, one of the benchmarks was for smoking cessation; however, if a patient did not smoke, he or she was not eligible to receive this benchmark. Therefore, in the weighted score calculation this benchmark was eliminated.

Primary outcomes were analyzed for 3 distinct outcomes: operative mortality, major morbidity, and overall mortality. Morbidity was defined according to The Society of Thoracic Surgeons (STS) database definitions. ${ }^{17} \mathrm{We}$ subdivided morbidity into major (adult respiratory distress syndrome, pulmonary emboli, reintubation, myocardial infarction, stroke, empyema, gastrointestinal complication requiring surgery, transfer to the intensive care unit [ICU] for any reason, and acute renal failure) or minor (all of the remaining morbidities listed in the STS thoracic database version 2.081). Operative mortality was defined as death within 30 days of operation or before discharge. The Institutional Review Board of the University of Alabama at Birmingham (UAB) approved this study and the prospective database used to record this information. Individual patient consent was obtained for inclusion in our prospective database but waived for this particular study.

In the clinic, patients were asked to fill out a demographic survey (as shown in Appendix 1) that obtained a wide variety of socioeconomic information. These included questions about their highest level of education and degree obtained, their median income over the past 20 years, and the number of dependents living in their home. This information was not shown to the surgical team.

Data were initially recorded in an Excel database (Microsoft Corp, Redmond, Wash) and analyzed with SAS version 9.1 (SAS Inc, Cary, NC). Categorical data are presented as percentages and continuous variables as medians. Fisher's exact test or the Pearson $\chi^{2}$ test was used to assess categorical data and the Wilcoxon test to evaluate continuous variables. Univariate and stepwise Wald multivariate logistic regression analyses of risk factors for operative mortality, major morbidity, and overall morbidity were performed by calculating an adjusted odds ratio with $95 \%$ confidence interval.

The following analyses were performed: (1) the types and percentage of benchmarks that were delivered, (2) the outcomes of patients who had all of the benchmarks delivered compared with those who did not, (3) the outcomes of patients who had all 10 critical benchmarks delivered compared with those that did not, (4) the outcomes of patients based on their weighted score, (5) a univariate analysis of outcomes based on known STS patient risk factors (age, gender, Zubrod score, American Society of Anesthesiologists class, diabetes mellitus, renal dysfunction, preoperative therapy, pulmonary function test results, and smoking history) and socioeconomic variables collected in our clinic, and (6) a multivariate analysis using variables that had a $P$ value of .08 or lower in the univariate analysis.

\section{RESULTS}

Between January 1, 2007, and December 31, 2009, 778 patients with NSCLC underwent elective rib-sparing, nerve-sparing thoracotomy with intent to cure by 1 general thoracic surgeon. The patient characteristics are shown in Table 2. The causes of operative mortality, major morbidity, and overall morbidity are shown in Table 3 . The first analysis performed was the types and percent of benchmarks that were delivered. Table 1 shows the individual benchmarks and the percent of patients that achieved each benchmark. Only $469(60 \%)$ patients had all of the benchmarks delivered. As shown in Table 1, the most frequently delivered benchmarks were those in the "day of surgery" category (mean, 99.8\%). Second most commonly delivered were the "intraoperative" benchmarks (mean, 97\%). The individual benchmark least likely to be delivered was benchmark 14 (cardiopulmonary rehabilitation program before surgery for selected patients), which was delivered in only $42 \%$ of patients. However, only 222 patients were eligible for this benchmark, as shown in Table 1.

The second analysis was to compare the mortality and morbidity of the 469 patients who had all of the benchmarks delivered compared with those who did not. There was no significant difference in the operative mortality between patients who did and did not achieve all of the benchmarks (9 patients, $2.0 \%$, versus 8 patients, $2.6 \%$, respectively; $P=.532$ ). Additionally, there was no significant differences in the major morbidity in patients who did and did not achieve all benchmarks $(9.2 \%)$ when compared with those who did not receive all of the benchmarks $(9.4 \% ; P=1.0)$. However, when the overall morbidity was analyzed, the 469 patients who had all 53 benchmarks delivered had a lower overall morbidity $(16 \%)$ than did the 309 patients who did not get all the benchmarks delivered $(44 \% ; P<.001)$.

The third analysis performed was patient outcomes, comparing the 693 (89\%) patients who had all 10 critical benchmark delivered and the $85(11 \%)$ patients who did not. The operative mortality was once again no different between the 2 groups $(13 / 693,1.9 \%$, vs $4 / 85,4.7 \%$, respectively; $P=.196)$. However, patients who had all of the critical benchmarks delivered had significantly less major 
TABLE 1. List of benchmarks and their classification and the number of patients who received them

\begin{tabular}{|c|c|c|c|c|c|c|c|}
\hline & Benchmark & Timing & Critical & $\begin{array}{l}\text { Impact } \\
\text { factor }\end{array}$ & Classification & $\begin{array}{c}\text { Patients eligible for } \\
\text { benchmark }(\%)\end{array}$ & $\begin{array}{c}\text { Eligible patients who } \\
\text { achieved benchmark }(\%)\end{array}$ \\
\hline \multicolumn{8}{|c|}{ Preoperative } \\
\hline 1 & $\begin{array}{l}\text { See patient in clinic } \leq 2 \text { weeks of patient } \\
\text { calling or referral physician calling for } \\
\text { appointment }\end{array}$ & Pre & No & 1 & Satisfaction & $100 \%$ & $100 \%$ \\
\hline 2 & $\begin{array}{l}\text { Integrated PET/CT performed } \leq 30 \text { days } \\
\text { of surgery }\end{array}$ & Pre & No & 4 & Quality & $100 \%$ & $83 \%$ \\
\hline 3 & $\begin{array}{l}\text { Computed tomography scan w/contrast } \\
\text { (5-mm columinated cuts) performed } \\
\leq 30 \text { days of surgery }\end{array}$ & Pre & No & 3 & Quality & $85 \%{ }^{(1)}$ & $100 \%$ \\
\hline 4 & $\begin{array}{l}\text { Have board-certified general and } \\
\text { cardiothoracic surgeon who performs } \\
\text { only general thoracic surgery clinically } \\
\text { stage and evaluate patient* }\end{array}$ & Pre & Yes & 5 & Quality & $100 \%$ & $100 \%$ \\
\hline 5 & $\begin{array}{l}\text { Clinical TNM stage determined and recorded } \\
\text { prior to surgery }\end{array}$ & Pre & Yes & 5 & Quality & $100 \%$ & $100 \%$ \\
\hline 6 & $\begin{array}{l}\text { Surgery and/or definitive staging procedures } \\
\text { offered } \leq 3 \text { weeks of seeing the surgeon }\end{array}$ & Pre & No & 3 & Quality & $93 \%^{(2)}$ & $100 \%$ \\
\hline 7 & $\begin{array}{l}\text { If tumor }>4 \mathrm{~cm} \text {, central, and/or has } \\
\text { a maxSUV of } 9 \text { or greater, mediastinal } \\
\text { staging procedures such as EUS-FNA } \\
\text { and/or EBUS performed with rapid on site } \\
\text { cytology and/or mediastinoscopy } \\
\text { performed }\end{array}$ & Pre & No & 4 & Quality & $37 \% \%^{(3)}$ & $100 \%$ \\
\hline 8 & $\begin{array}{l}\text { If maxSUV of lymph node is }>50 \% \text { of } \\
\text { primary tumor, biopsy of that node is } \\
\text { performed (unless it is an isolated \#5 or } \\
\# 6 \text { lymph node in selected patients) }\end{array}$ & Pre & No & 3 & Quality & $40 \%{ }^{(3)}$ & $100 \%$ \\
\hline 9 & $\begin{array}{l}\text { Anesthesia to evaluate patient on same day of } \\
\text { clinic appointment }\end{array}$ & Pre & No & 1 & Satisfaction & $92 \%{ }^{(4)}$ & $68 \%$ \\
\hline 10 & $\begin{array}{l}\text { Stress test performed for patients with } \\
\text { a smoking history of } \geq 20 \text { pack-years or } \\
\text { have history of coronary artery disease }\end{array}$ & Pre & No & 4 & Quality & $72 \%{ }^{(5)}$ & $97 \%$ \\
\hline 11 & $\begin{array}{l}\text { Cardiology clearance if patient has abnormal } \\
\text { stress test }\end{array}$ & Pre & No & 3 & Quality & $16 \%{ }^{(6)}$ & $100 \%$ \\
\hline 12 & $\begin{array}{l}\text { Full set of pulmonary function tests } \\
\text { including } \mathrm{FEV}_{\mathbf{1}} \%, \text { DLCO } \% \text {, and } \\
\text { DLCO/VA } \% \leq 30 \text { days of surgery } *\end{array}$ & Pre & No & 3 & Quality & $100 \%$ & $89 \%$ \\
\hline 13 & $\begin{array}{l}\text { Smoking cessation classes and/or } \\
\text { prescription and pamphlets given } \\
\geq 2 \text { weeks before surgery }\end{array}$ & Pre & No & 5 & Quality & $57 \%{ }^{(7)}$ & $88 \%$ \\
\hline 14 & $\begin{array}{l}\text { Cardiopulmonary rehabilitation program for } \\
1 \text { month before surgery in selected patients }\end{array}$ & Pre & Yes & 5 & Quality & $26 \%{ }^{(8)}$ & $42 \%$ \\
\hline \multicolumn{8}{|c|}{ Day of surgery } \\
\hline 15 & Admitted the day of surgery & DOS & No & 1 & Satisfaction & $100 \%$ & $98 \%$ \\
\hline 16 & $\begin{array}{l}\text { Have updated history and physical } \\
\text { examination documented before surgery }\end{array}$ & DOS & No & 2 & Quality & $100 \%$ & $100 \%$ \\
\hline 17 & $\begin{array}{l}\text { Administer a dose of antibiotics before skin } \\
\text { incision and write postop order to stop } \\
\text { antibiotics after first dose }\end{array}$ & DOS & No & 2 & Quality & $100 \%$ & $100 \%$ \\
\hline 18 & $\begin{array}{l}\text { Time out to ensure the correct procedure is } \\
\text { carried out }\end{array}$ & DOS & No & 2 & Quality & $100 \%$ & $100 \%$ \\
\hline 19 & $\begin{array}{l}\text { Board-certified cardiothoracic } \\
\text { anesthesiologist present during induction* }\end{array}$ & DOS & Yes & 5 & Quality & $100 \%$ & $100 \%$ \\
\hline 20 & Perform bronchoscopy before skin incision & DOS & No & 3 & Quality & $100 \%$ & $100 \%$ \\
\hline
\end{tabular}


TABLE 1. Continued

\begin{tabular}{|c|c|c|c|c|c|c|c|}
\hline & Benchmark & Timing & Critical & $\begin{array}{l}\text { Impact } \\
\text { factor }\end{array}$ & Classification & $\begin{array}{l}\text { Patients eligible for } \\
\text { benchmark }(\%)\end{array}$ & $\begin{array}{c}\text { Eligible patients who } \\
\text { achieved benchmark }(\%)\end{array}$ \\
\hline 21 & $\begin{array}{l}\text { During mediastinoscopy, at least } 2 \text { lymph } \\
\text { node stations biopsied and frozen } \\
\text { pathology provided }\end{array}$ & DOS & No & 4 & Quality & $52 \%{ }^{(9)}$ & $100 \%$ \\
\hline 22 & $\begin{array}{l}\text { Patients who are } \mathrm{N} 2 \text { positive have their care } \\
\text { discussed at multispecialty cancer } \\
\text { conference OR Patients who are N2 } \\
\text { negative who are not to have neo-adjuvant } \\
\text { therapy have primary tumor resected } \\
\text { within } 1 \text { week of mediastinoscopy and } \\
\text { within } 2 \text { weeks of EBUS and EUS-FNA }\end{array}$ & DOS & No & 4 & Quality & $100 \%$ & $100 \%$ \\
\hline \multicolumn{8}{|c|}{ Intraoperative } \\
\hline 23 & $\begin{array}{c}\text { Patients who are } \leq 70 \text { years of age get } \\
\text { epidural, }>70 \text { years get pain pump }\end{array}$ & Intra & No & 3 & Quality & $100 \%$ & $94 \%$ \\
\hline 24 & $\begin{array}{l}\text { Intraoperative injection of subcutaneous } \\
\text { heparin }\end{array}$ & Intra & No & 3 & Quality & $100 \%$ & $98 \%$ \\
\hline 25 & $\begin{array}{l}\text { Attending surgeon makes skin incision, is } \\
\text { present for opening, for dissection of } \\
\text { and ligation of all major vessels, and for } \\
\text { lymph node removal. Also present for } \\
\text { chest closure up to the skin* }\end{array}$ & Intra & Yes & 5 & Quality & $100 \%$ & $100 \%$ \\
\hline 26 & Family called when incision is made & Intra & No & 1 & Satisfaction & $90 \%{ }^{(10)}$ & $98 \%$ \\
\hline 27 & $\begin{array}{l}\text { Had a rib-sparing, muscle-sparing, nerve- } \\
\text { sparing thoracotomy }\end{array}$ & Intra & Yes & 5 & Quality & $100 \%$ & $100 \%$ \\
\hline 28 & $\begin{array}{l}\text { Palpation of all nonresected lobes of the } \\
\text { ipsilateral lung }\end{array}$ & Intra & No & 3 & Quality & $100 \%$ & $100 \%$ \\
\hline 29 & $\begin{array}{l}\text { Complete thoracic lymphadenectomy } \\
\text { performed for patients with lung cancer on } \\
\text { the right side; resection of all of the } 2 \mathrm{R} \text {, } \\
4 \mathrm{R}, 7,8 \text {, and } 9 \text { and on the left side } \\
\text { resection of the } 4 \mathrm{~L}, 5,6,7,8 \mathrm{~L} \text {, and } 9 \mathrm{~L} \text { and } \\
\text { removal of all appropriate } \mathrm{N} 1 \text { nodes }\end{array}$ & Intra & No & 4 & Quality & $100 \%$ & $100 \%$ \\
\hline 30 & $\begin{array}{l}\text { Lobectomy performed for all patients except } \\
\text { those with bronchoalveolar carcinoma, } \\
\text { those with a primary tumor }>2 \mathrm{~cm} \text {, or } \\
\text { selected patients with low DLCO } \% \text { or } \\
\mathrm{FEV}_{1} \%\end{array}$ & Intra & No & 4 & Quality & $100 \%$ & $100 \%$ \\
\hline 31 & $\begin{array}{l}\text { Negative bronchial margin, verified in the } \\
\text { operating room by frozen section }\end{array}$ & Intra & No & 4 & Quality & $100 \%$ & $100 \%$ \\
\hline 32 & $\begin{array}{l}\text { Negative stapled margins verified in the } \\
\text { operative room by frozen section, i.e., } \\
\text { an complete resection }\end{array}$ & Intra & No & 4 & Quality & $100 \%$ & $100 \%$ \\
\hline 33 & $\begin{array}{l}\text { One chest tube used for lobectomy, unless } \\
\text { clinically scenario documented why } 2 \\
\text { were used }\end{array}$ & Intra & No & 3 & Quality & $100 \%$ & $83 \%$ \\
\hline 34 & $\begin{array}{l}\text { Chest tube placed to wall suction on the day } \\
\text { of surgery, to water seal next morning }\end{array}$ & Intra & No & 3 & Quality & $100 \%$ & $94 \%$ \\
\hline 35 & $\begin{array}{l}\text { Pulmonary resection performed }<1 \text { hour } \\
40 \text { minutes, skin to skin in patients } \\
\text { who have not had neoadjuvant } \\
\text { chemotherapy, radiation, or prior } \\
\text { ipsilateral thoracotomy; otherwise } \\
\text { within } 2.5 \text { hours* }\end{array}$ & Intra & Yes & 5 & Quality & $100 \%$ & $87 \%$ \\
\hline 36 & Skin incision time before 14:00 & Intra & No & 2 & Satisfaction & $95 \%$ & $95 \%$ \\
\hline 37 & Blood loss $<125 \mathrm{~mL}$ during operation* & Intra & Yes & 5 & Quality & $100 \%$ & $96 \%$ \\
\hline
\end{tabular}




\begin{tabular}{|c|c|c|c|c|c|c|c|}
\hline & Benchmark & Timing & Critical & $\begin{array}{l}\text { Impact } \\
\text { factor }\end{array}$ & Classification & $\begin{array}{l}\text { Patients eligible for } \\
\text { benchmark }(\%)\end{array}$ & $\begin{array}{c}\text { Eligible patients who } \\
\text { achieved benchmark }(\%)\end{array}$ \\
\hline 38 & $\begin{array}{l}\text { No packed red blood cell transfusion } \\
\text { given in the operating room* }\end{array}$ & Intra & Yes & 5 & Quality & $99 \%{ }^{(11)}$ & $98 \%$ \\
\hline 39 & $\begin{array}{l}\text { Needle and sponge count before leaving } \\
\text { the operating room }\end{array}$ & Intra & No & 2 & Quality & $100 \%$ & $100 \%$ \\
\hline 40 & $\begin{array}{l}\text { Chest radiography performed in recovery } \\
\text { room }\end{array}$ & Intra & No & 2 & Quality & $100 \%$ & $100 \%$ \\
\hline \multicolumn{8}{|c|}{ Postoperative } \\
\hline 41 & $\begin{array}{l}\text { Admitted directly to a specialized floor } \\
\text { with nurses experienced in caring for } \\
\text { patients who have had a pulmonary } \\
\text { resection (avoid ICU admission)* }\end{array}$ & Post & Yes & 5 & Quality & $100 \%$ & $96 \%$ \\
\hline 42 & $\begin{array}{l}\text { Pain service (anesthesia) involved in patients } \\
\text { postop care in patients with epidural }\end{array}$ & Post & No & 3 & Quality & $100 \%$ & $99 \%$ \\
\hline 43 & $\begin{array}{l}\text { Daily subcutaneous heparin injections } \\
\text { ordered and compression stockings worn } \\
\text { at all times }\end{array}$ & Post & No & 3 & Quality & $100 \%$ & $96 \%$ \\
\hline 44 & $\begin{array}{l}\text { Appropriate consults ordered: social work, } \\
\text { nutrition, anesthesia, respiratory, physical } \\
\text { therapy }\end{array}$ & Post & No & 3 & Satisfaction & $100 \%$ & $87 \%$ \\
\hline 45 & $\begin{array}{l}\text { Respiratory therapists at bedside at least } 2 \\
\text { times per day }\end{array}$ & Post & No & 5 & Quality & $100 \%$ & $100 \%$ \\
\hline 46 & $\begin{array}{l}\text { Chest radiograph ordered only as needed } \\
\text { and chest posteroanterior/lateral film } \\
\text { ordered after last chest tube is removed }\end{array}$ & Post & No & 2 & Quality & $100 \%$ & $100 \%$ \\
\hline 47 & $\begin{array}{l}\text { Discharge by POD 4, unless social issues } \\
\text { delay discharge* }\end{array}$ & Post & Yes & 5 & Quality & $100 \%$ & $88 \%$ \\
\hline 48 & $\begin{array}{l}\text { Cardiology consult ordered if atrial } \\
\text { arrhythmia lasts }>24 \text { hours, or elevated } \\
\text { cardiac enzymes }\end{array}$ & Post & No & 3 & Quality & $15 \%$ & $100 \%$ \\
\hline 49 & $\begin{array}{l}\text { Follow-up appointment within } 3 \text { weeks } \\
\text { postop }\end{array}$ & Post & No & 1 & Satisfaction & $100 \%$ & $87 \%$ \\
\hline 50 & $\begin{array}{l}\text { Prescription for pain medication given } \\
\text { before discharge }\end{array}$ & Post & No & 2 & Satisfaction & $100 \%$ & $100 \%$ \\
\hline 51 & $\begin{array}{l}\text { Patient sent home with a telephone number } \\
\text { to be able to contact a thoracic team } \\
\text { member } 24 \text { hours a day, } 7 \text { days a week }\end{array}$ & Post & No & 1 & Satisfaction & $100 \%$ & $100 \%$ \\
\hline 52 & $\begin{array}{l}\text { Pathology report available by POD } 3 \text { or } \\
\text { before discharge. Otherwise patient } \\
\text { instructed to call office for pathology } \\
\text { results after discharge }\end{array}$ & Post & No & 1 & Satisfaction & $100 \%$ & $80 \%$ \\
\hline 53 & $\begin{array}{l}\text { An appointment with oncologist }<4 \text { weeks } \\
\text { if postop adjuvant treatment indicated }\end{array}$ & Post & No & 2 & Quality & $52 \%^{(12)}$ & $89 \%$ \\
\hline
\end{tabular}

Reasons that some patients were not eligible for benchmarks $(<100 \%)$ : (1) Creatinine too high for some patients to be eligible for computed tomography scan. (2) Some patients not able to go right to surgery. Patient's whose schedules did not allow or if they were not physically fit, were not eligible. (3) Some patients had smaller tumor or lower maxSUV. (4) Some patients arrived to clinic too late and thus could not make it to anesthesia clinic before closing time. (5) Some patients were nonsmokers or smoked less than this amount. (6) Some patients had normal stress test, no significant history of heart disease, or no history of smoking. (7) Some patients were nonsmokers or had already stopped smoking. (8) Patients with normal stress test were not eligible. (9) Some patients did not have a mediastinoscopy. (10) Operating room staff forgot to call or family unavailable/unable to be located. (11) Patients who were Jehovah's Witnesses or refused blood products were not eligible. (12) Some patients did not require additional treatment. PET, Positron emission tomography; $C T$, computed tomography; $\max S U V$, maximum standardized uptake value; $E U S$, endoscopic ultrasound; $F N A$, fine needle aspiration; $E B U S$, endobronchial ultrasound; $F E V_{l} \%$, percent forced expiratory volume in 1 second; $V A$, alveolar volume; $D L C O \%$, percent diffusion lung capacity for carbon monoxide; ICU, intensive care unit; $P O D$, postoperative day; $D O S$, day of surgery. *Critical benchmarks.

morbidity $(8 \%$ vs $16 \% ; P=.015)$ as well as less overall morbidity $(25 \%$ compared with $41 \% ; P<.003)$.

The fourth analysis compared the weighted scores for each patient. The weighted score was calculated by using only the "quality of care" benchmarks and benchmarks that all patients were eligible to receive. We then multiplied it by the impact factor for each one of these benchmarks to generate a total weighted score for each patient. The highest 
TABLE 2. The patient characteristics are shown below $(N=778)$

\begin{tabular}{|c|c|}
\hline Age (median years) \pm SD, range & $67 \pm 10(19-86)$ \\
\hline \multicolumn{2}{|l|}{ Gender } \\
\hline Male & $388(50 \%)$ \\
\hline Female & $390(50 \%)$ \\
\hline Zubrod score, median, range & $1(0-2)$ \\
\hline ASA class, median, range & $3(2-4)$ \\
\hline \multicolumn{2}{|l|}{ Type of pulmonary resection } \\
\hline Pneumonectomy & $15(2 \%)$ \\
\hline Lobectomy/bilobectomy/sleeve lobectomy & $499(61 \%)$ \\
\hline Sublobar resection & $264(34 \%)$ \\
\hline \multicolumn{2}{|l|}{ Pulmonary function tests } \\
\hline $\mathrm{FEV}_{1} \%($ median $) \pm \mathrm{SD}$ & $78 \% \pm 12$ \\
\hline $\mathrm{DLCO} \%($ median $) \pm \mathrm{SD}$ & $89 \% \pm 14$ \\
\hline $\begin{array}{l}>\text { Twenty pack-year smoking history and current } \\
\text { smoker (smoked within past month) }\end{array}$ & $276(35 \%)$ \\
\hline \multicolumn{2}{|l|}{ Received neoadjuvant therapy } \\
\hline Yes & $109(13.6 \%)$ \\
\hline No & $669(86.4 \%)$ \\
\hline \multicolumn{2}{|l|}{ History of coronary artery disease } \\
\hline Yes & $171(22 \%)$ \\
\hline No & $607(78 \%)$ \\
\hline \multicolumn{2}{|l|}{ History of preoperative renal dysfunction (dialysis) } \\
\hline Yes & $53(6.8 \%)$ \\
\hline No & $725(93.2 \%)$ \\
\hline \multicolumn{2}{|l|}{ Diabetes mellitus } \\
\hline Yes & $120(15.4 \%)$ \\
\hline No & $658(84.6 \%)$ \\
\hline
\end{tabular}

patient-weighted score was 118 points and the lowest was 102. Weighted score was not associated with operative mortality nor was it associated with major morbidity. However, more patients who had overall morbidity had a significantly lower weighted score (average score, 113) than did those patients without any morbidity (average score, $116.7 ; P<.001$ ).

Table 4 shows the results of the fifth analysis, which was univariate factors that assessed outcomes based on known STS risk factors and on the patient's socioeconomic factors. As shown in Table 4, only age, smoking status, percent forced expiratory volume in 1 second, types of pulmonary resection, and coronary artery disease were significantly associated with mortality on univariate analysis. When major morbidity was analyzed, several factors were associated with a worse outcome: patients who did not receive all of the critical benchmarks, age, male gender, higher Zubrod score, lower percent diffusion lung capacity for carbon monoxide, current smoker, history of coronary artery disease, types of pulmonary resection, and residing either by themselves or with 1 other person were significantly associated with major morbidity. When overall morbidity was analyzed, factors that were statistically associated with worse outcomes were age, male sex, lower percent forced expiratory volume in 1 second, lower percent diffusion lung capacity for carbon monoxide, current smokers, types of pulmonary resection, those who lived alone or with only 1 other person, patient's annual household income less than $\$ 25,000$, not having all the benchmarks or all of the critical benchmarks delivered, and have a lower weighted score.

The results of the sixth analysis are shown in Table 5. This is the multivariate analysis of the 3 types of outcomes. It shows that only smoking status and history of coronary artery disease remained significant predictors of operative mortality. Predictors of major morbidity on multivariate analysis were critical benchmarks, coronary artery disease, smoking, and age. Finally, multivariate predictors of overall morbidity were critical benchmarks, weighted score, coronary artery disease, types of pulmonary resection, and age. The odds ratio shows that coronary artery disease was the most strongly associated factor to overall morbidity.

\section{DISCUSSION}

Reimbursement in thoracic surgery has already been altered by the concept of pay for performance. Medicare has proposed to pay $2 \%$ additional reimbursement to cardiothoracic surgeons who document some of the 179 (soon to be 216) PQRI measures. ${ }^{18}$ Traditionally, private insurers follow Medicare's lead. Thus reimbursement for quality of care instead of quantity of care is already here and its role is likely to expand. Our study attempts to examine the extreme of this system. This study was designed to list many aspects of care that a patient with NSCLC who was referred to a general thoracic surgeon and who went on to pulmonary resection could get. It then critically evaluated whether these benchmarks could be delivered and which ones were easy to deliver and which were not. Then we analyzed how their delivery affected outcomesmortality, overall morbidity, and major morbidity.

One of the major findings in this study is that most of the 53 subjectively determined benchmarks could be delivered. We divided the benchmarks into 4 categories on the basis of the temporal aspect of care. In addition, we also divided them into 2 larger categories: those concerned with patient and family satisfaction and those with quality of care. Disappointingly, only $60 \%$ of patients had all of their benchmarks delivered despite our goal to make this $100 \%$ for every patient. The most common ones that could be consistently delivered were the "day of surgery" and "intraoperative" benchmarks. This makes sense inasmuch as these are the ones over which the surgeon usually has the greatest control. The ones most commonly not delivered were those that dealt with the compliance of patients, such as to perform a cardiopulmonary rehabilitation program for 1 month before surgery. One reason for failure is that some concerned socioeconomic factors such as transportation, even though rehabilitation was always offered to the center closest to their home. Importantly, however, $89 \%$ of patients received all 10 critical benchmarks and $98 \%$ received at least 9 of the 10 . 
TABLE 3. Morbidity and mortality (some patients had overlapping morbidities)

Major morbidity (includes causes of mortality, indicated by $*)(N=72)$

Pulmonary

Acute respiratory distress syndrome (reintubated) $\times 4 *$
Pulmonary embolism $\times 3$ (death in $2 *)$ Empyema $\times 3$
"Pneumonia" requiring transfer to ICU $\times 4$
Respiratory distress/hypoxia $\times 3$ (requiring return to operating
room for bronchcoscopy)
Pneumothorax requiring intervention $\times 2$,
Respiratory arrest $\times 2$ (death in $1 *)$
Prolonged intubation postoperatively $\times 2$
Myocardial infarction $\times 5$ (death in $2 *)$
Ventricular tachycardia*
Cardiac arrest*
Cardiac arrhythmia requiring transfer to coronary care unit
Ileus/megacolon*
Ileus $\times 4$
Ischemic duodenum*
Ischemic colon*
Gastrointestinal bleeding*
Seizure $\times 2$ (death in $1 *)$
Cerebrovascular accident $\times 2 *$
Transient ischemic attack $\times 2$
Acute renal failure $\times 4$
Pyelonephritis

Other

\author{
Narcotic withdrawal requiring admit to ICU* \\ Chylothorax $\times 7$ \\ Bleeding/high output - take back to operative room for \\ exploration/wash out $\times 2$ \\ Sudden death (noncardiac) \\ Transferred to ICU/made DNR $\times 3$ \\ Deep vein thrombosis requiring treatment $\times 2$ \\ Sepsis $\times 2 *$ \\ Multisystem organ failure $(\mathrm{DNR}) \times 3^{*}$ \\ High fever of unknown origin/requiring intravenous antibiotics \\ Cellulitis
}

Morbidity (includes all major morbidity and mortality)

$$
(\mathrm{N}=\mathbf{2 1 0})
$$

Air leak-discharge with chest tube $\times 9$

Subcutaneous emphysema $\times 4$

Pulmonary edema $\times 2$

Mucous plug/atelectasis (bedside bronchcoscopy) $\times 4$

Atrial fibrillation $\times 68$

Chest pain/elevated cardiac enzymes $\times 4$

Small bowel obstruction $\times 2$

Delirium $\times 5$

Excessive somnolence $\times 2$

Urinary tract infection $\times 6$

Urinary retention $\times 12$

Elevated creatinine $\times 2$

Nausea/vomiting (prolonged hospital stay) $\times 9$

Alcohol withdrawal $\times 2$

Transient hoarseness $\times 2$

Deep vein thrombosis (no treatment required)

Coagulopathy $\times 2$

Postoperative blood transfusion $\times 2$

Pain issues (delayed discharge) $\times 4$

$I C U$, Intensive care unit; $D N R$, do not resuscitate.

The benchmarks we selected were subjectively chosen on the basis of our experience and on some of the previous literature using quality improvement guides such as the American College of Surgeon's NSQIP (National Surgery Quality Improvement Program) and the POSSUM (Physiological and Operative Severity Score for the enUmeration of Morbidity and mortality) score. ${ }^{19,20}$ Similar to those criteria, our benchmarks are prone to subjectivity and thus an obvious criticism of this study. ${ }^{21}$ However, we believe that some of the benchmarks we selected, such as the delivery of an operation in under 1.5 hours and requiring no blood transfusion, are probably better markers for "quality care" than those currently selected by Medicare (ie, stopping antibiotics after postoperative day 1 or ensuring that antibiotics are given before skin incision).
Another important finding in this study is that the delivery of benchmarks, even when critical benchmarks were considered, had no statistically significant impact on operative mortality. However, there was a trend toward mortality reduction. This probably is because, as Cassivi and colleagues ${ }^{9}$ wrote, "operative mortality, although easily definable, is difficult to use as a measure of quality of care as it is, fortunately, an uncommon event for most [pulmonary resections] and therefore underpowered." However, we found that the 693 patients who had delivery of all 10 critical benchmarks had significantly lower postoperative major morbidity. This finding, though, may be in part due to the fact that some of the critical benchmarks may be nothing more than surrogate markers of not having had a complication. For example, benchmark 41 is "avoid going to the ICU..." and it would not be achieved in a patient who is 
TABLE 4. These variables were entered into a univariate analysis to determine association with postoperative mortality, major morbidity, and overall morbidity

\begin{tabular}{|c|c|c|c|c|c|c|}
\hline & $\begin{array}{c}\text { Mortality } \\
(N=17)\end{array}$ & $P$ value & $\begin{array}{l}\text { Major morbidity } \\
\quad(\mathbf{N}=72)\end{array}$ & $P$ value & $\begin{array}{l}\text { Overall morbidity } \\
\qquad(\mathbf{N}=\mathbf{2 1 0}) \\
\end{array}$ & $P$ value \\
\hline \multicolumn{7}{|l|}{ Achieved all benchmarks } \\
\hline Yes, $\mathrm{N}=469$ & $9(2.0 \%)$ & .532 & $43(9.2 \%)$ & 1.00 & $75(16 \%)$ & $<.001$ \\
\hline No, $\mathrm{N}=309$ & $8(2.6 \%)$ & & $29(9.4 \%)$ & & $135(44 \%)$ & \\
\hline \multicolumn{7}{|l|}{ Achieved all critical benchmarks } \\
\hline Yes, $\mathrm{N}=693$ & $13(1.9 \%)$ & .196 & $58(8 \%)$ & .015 & $175(25 \%)$ & .003 \\
\hline No, $\mathrm{N}=85$ & $4(4.7 \%)$ & & $14(16 \%)$ & & $35(41 \%)$ & \\
\hline \multicolumn{7}{|l|}{ Weighted score (median 117) } \\
\hline$<117, \mathrm{~N}=389$ & $11(2.8 \%)$ & .353 & $43(11 \%)$ & .08 & $162(42 \%)$ & $<.001$ \\
\hline$\geq 117, N=389$ & $6(1.5 \%)$ & & $29(7.5 \%)$ & & $48(12 \%)$ & \\
\hline \multicolumn{7}{|l|}{ Age (median age $67 \mathrm{y}$ ) } \\
\hline$<67, N=389$ & $13(3.3 \%)$ & .044 & $49(12.6 \%)$ & $<.001$ & $143(37 \%)$ & .001 \\
\hline$\geq 67, N=389$ & $4(1.0 \%)$ & & $23(6 \%)$ & & $67(17.2 \%)$ & \\
\hline \multicolumn{7}{|l|}{ Gender } \\
\hline Male, $\mathrm{N}=388$ & $11(2.8 \%)$ & .232 & $46(11.8 \%)$ & .013 & $121(58 \%)$ & .018 \\
\hline Female, $N=390$ & $6(1.5 \%)$ & & $26(6.7 \%)$ & & $89(42 \%)$ & \\
\hline \multicolumn{7}{|l|}{ Zubrod score } \\
\hline 1. $\mathrm{N},=597$ & $12(2.0 \%)$ & .563 & $63(11 \%)$ & .027 & $157(26 \%)$ & .445 \\
\hline $2.2, \mathrm{~N}=181$ & $5(2.7 \%)$ & & $9(4.9 \%)$ & & $53(29 \%)$ & \\
\hline \multicolumn{7}{|l|}{$\mathrm{FEV}_{1} \%(78 \%$ median $)$} \\
\hline$<8 \%, \mathrm{~N}=389$ & $13(3.3 \%)$ & .047 & $43(10.3 \%)$ & .083 & $161(41 \%)$ & $<.001$ \\
\hline$\geq 78 \%, N=389$ & $4(1.0 \%)$ & & $32(8.2 \%)$ & & $49(13 \%)$ & \\
\hline \multicolumn{7}{|l|}{ DLCO $\%(89 \%$ median $)$} \\
\hline$<89 \%, N=389$ & $12(3 \%)$ & .059 & $55(14 \%)$ & $<.001$ & $72(18.5 \%)$ & $<.001$ \\
\hline$\geq 89 \%, N=389$ & $5(1.2 \%)$ & & $17(4.4 \%)$ & & $138(35 \%)$ & \\
\hline $\begin{array}{l}>\text { Twenty pack-year smoking history AND } \\
\text { current smoker, } \mathrm{N}=276\end{array}$ & $14(5.0 \%)$ & $<0.001$ & $41(14.9 \%)$ & $<0.001$ & $95(45 \%)$ & $<0.001$ \\
\hline \multicolumn{7}{|l|}{ Coronary artery disease } \\
\hline Yes, $\mathrm{N}=171$ & $12(7.0 \%)$ & $<.001$ & $29(17 \%)$ & $<.001$ & $52(25 \%)$ & .297 \\
\hline No, $N=607$ & $5(0.8 \%)$ & & $43(7 \%)$ & & $158(26 \%)$ & \\
\hline \multicolumn{7}{|l|}{ Renal dysfunction } \\
\hline Yes, $\mathrm{N}=53$ & $2(3.8 \%)$ & .324 & $5(9.4 \%)$ & .963 & $15(7 \%)$ & \\
\hline No, $N=725$ & $15(2.1 \%)$ & & $67(9.2 \%)$ & & $195(26.8 \%)$ & .263 \\
\hline \multicolumn{7}{|l|}{ Diabetes mellitus } \\
\hline Yes, $\mathrm{N}=120$ & $4(3.3 \%)$ & .316 & $14(15 \%)$ & .321 & $27(13 \%)$ & .274 \\
\hline No, $N=658$ & $13(2.0 \%)$ & & $58(8.2 \%)$ & & $183(27.8 \%)$ & \\
\hline \multicolumn{7}{|l|}{ Neoadjuvant therapy } \\
\hline Yes, $\mathrm{N}=109$ & $2(1.8 \%)$ & 1.00 & $7(6.4 \%)$ & .356 & $25(12 \%)$ & .463 \\
\hline No, $N=669$ & $15(2.2 \%)$ & & $65(9.7 \%)$ & & $185(27.6 \%)$ & \\
\hline Type of pulmonary resection & & .011 & & & & \\
\hline Pneumonectomy, $\mathrm{N}=15$ & $2(13 \%)$ & & $5(33.3 \%)$ & .004 & $13(87 \%)$ & $<.001$ \\
\hline Lobectomy/Bilobectomy/sleeve, $\mathrm{N}=499$ & $9(1.9 \%)$ & & $42(8.4 \%)$ & & $139(28 \%)$ & \\
\hline Sublobar, $N=264$ & $6(2.3 \%)$ & & $24(9.0 \%)$ & & $58(21 \%)$ & \\
\hline \multicolumn{7}{|l|}{ Highest education* } \\
\hline Twelfth grade or less, $\mathrm{N}=297$ & $8(2.7 \%)$ & .550 & $39(13 \%)$ & .051 & $78(37 \%)$ & .197 \\
\hline Some college or college graduate, $\mathrm{N}=281$ & $2(1.4 \%)$ & & $20(7 \%)$ & & $65(31 \%)$ & \\
\hline Graduate degree, $N=120$ & $3(2.5 \%)$ & & $13(11 \%)$ & & $67(32 \%)$ & \\
\hline Annual household income* & & & & .588 & & \\
\hline$<\$ 25,000, \mathrm{~N}=346$ & $8(2.3 \%)$ & .189 & $29(9 \%)$ & & $122(58 \%)$ & $<.001$ \\
\hline$\$ 25,001-\$ 50,000, \mathrm{~N}=327$ & $5(1.5 \%)$ & & $35(11 \%)$ & & $71(34 \%)$ & \\
\hline$>\$ 50,000, N=85$ & $4(4.7 \%)$ & & $8(9.4 \%)$ & & $17(8 \%)$ & \\
\hline \multicolumn{7}{|l|}{ No.of persons in household (includes patient) } \\
\hline $1-2, \mathrm{~N}=349$ & $6(1.7 \%)$ & .470 & $43(12.3 \%)$ & .011 & $110(52 \%)$ & .013 \\
\hline$\geq 3, N=429$ & $11(2.6 \%)$ & & $29(6.8 \%)$ & & $100(48 \%)$ & \\
\hline
\end{tabular}


TABLE 5. The variables in this table remained significant predictors after multivariate analysis of operative mortality, major morbidity and overall morbidity

\begin{tabular}{lc}
\hline \multicolumn{1}{c}{ Variables } & Odds ratio $(\mathbf{9 5} \% \mathbf{C I})$ \\
\hline $\begin{array}{l}\text { Operative mortality } \\
\text { Smoking history }>20 \text { patient-years and } \\
\quad \text { current smoker }\end{array}$ & $2.1(1.08-4.53)$ \\
$\quad$ Coronary artery disease & $1.8(1.17-8.51)$ \\
Major morbidity & \\
$\quad$ All critical benchmarks achieved & $2.2(1.53-3.55)$ \\
Coronary artery disease & $2.4(1.68-3.53)$ \\
Smoking history $>20$ patient-years and & $1.9(1.80-3.74)$ \\
$\quad$ current smoker & \\
Age $\geq 67$ years & $1.5(1.13-2.72)$ \\
Overall morbidity & \\
All critical benchmarks achieved & $1.7(1.14-2.70)$ \\
Weighted score $<117$ & $2.1(1.35-3.44)$ \\
Coronary artery disease & $2.9(2.5-4.17)$ \\
Type of pulmonary resection & $1.3(1.14-2.85)$ \\
Age $\geq 67$ years & $1.8(1.21-2.70)$ \\
\hline CI, Confidence interval.
\end{tabular}

doing well. Another critical benchmark, number 47 , is "discharge by postoperative day 4 or sooner." This too is often a surrogate for patients who have some sort of postoperative complications. For this reason we do not want to overstate the importance of benchmark delivery on our findings because of the subjectively selected benchmarks, the weighted score, or the fact it examined one specialized practice. Yet, benchmark delivery did reduce perioperative morbidity and produce a trend toward lower mortality.

Inasmuch as we wanted to determine whether the benchmarks or pay for performance concept could be teased out as a predictor of morbidity, we performed a weighted analysis. We assigned scores from 1 to 5 for the importance of each benchmark based on its impact for outcomes. We only considered benchmarks that all patients were eligible to receive and benchmarks that only dealt with quality of care issues. Although this weighted score was statistically related to overall morbidity and major morbidity, it too was not associated with operative mortality. Finally, we found that the lack of delivery of all 10 of the critical benchmarks was associated with increased major morbidity and overall morbidity.

The strengths of this study were the large cohort over a relatively short temporal period, minimization of variability by having only 1 surgeon and 1 surgical team, and the availability of actual socioeconomic data (rather than using surrogate markers that are often seen in large registries such as Surveillance Epidemiology and End Results or Medicare databases). The limitations are that the benchmarks were subjectively selected and that this scoring system has not yet been validated.

In conclusion, in this single-center study we found that benchmarks that represent both high quality of care and high patient satisfaction for those with NSCLC can be deliv- ered. This is especially true for those that are concerned with care just before surgery and those benchmarks that are carried out intraoperatively. The vast majority of patients can receive all of the critical benchmarks. This reduces major morbidity. The delivery of all 53 of the subjectively chosen metrics of quality that we selected also reduced perioperative morbidity. The delivery of the benchmark did lead toward a trend of lower operative mortality, but only patient characteristics such as smoking history and coronary artery disease were predictors on multivariate analysis. Importantly, socioeconomic factors that are too infrequently considered significant also were predictors of poor patient outcomes. We found that having more than 1 other person in the household was a univariate predictor of both increased overall and major morbidity. Having an annual household income of less than $\$ 25,000$ was also a univariate predictor of increased overall morbidity. Given these findings, not only is the "quality of the health care provider" important but the "quality of the patient" should not be underestimated. Carefully designed and analyzed multi-institutional studies are needed to better understand these complicated and multifactorial issues. The concepts of benchmarks, quality of care, and pay for performance in general thoracic surgery, all of which are part of our future, require further study.

\section{References}

1. Institute of Medicine. Crossing the quality chasm: a new health system for the 21st century. Washington (DC): National Academies Press; 2001.

2. Baker G, Carter B. Introduction to case studies in health plan pay-for-performance. Washington (DC): Atlantic Information Services; 2004.

3. Hillman AL, Ripley K, Goldfarb N, Nuamah I, Weiner J, Lusk E. Physician financial incentives and feedback: failure to increase cancer screening in Medicaid managed care. Am J Public Health. 1998;88:1699-701.

4. Grady KE, Lemkau JP, Lee NR, Caddell C. Enhancing mammography referral in primary care. Prev Med. 1997;26:791-800.

5. Glickman SW, Ou FS, DeLong ER, Roe MT, Lytle BL, Mulgund J, et al. Pay for performance, quality of care, and outcomes in acute myocardial infarction. JAMA. 2007;297:2373-80.

6. Nahra TA, Reiter KL, Hirth RA, Shermer JE, Wheeler JR. Cost-effectiveness of hospital pay-for-performance incentives. Med Care Res Rev. 2006;63: 49S-72.

7. Gilmore AS, Zhao Y, Kang N, Ryskina KL, Legorreta AP, Taira DA, et al. Patient outcomes and evidence-based medicine in a preferred provider organization setting: a six-year evaluation of a physician pay-for-performance program. Health Serv Res. 2007;42:2140-59.

8. Curtin K, Beckman H, Pankow G, Milillo Y, Green RA. Return on investiment in pay for performance: a diabetes case study. J Healthc Manag. 2006;51:365-76.

9. Cassivi SD, Allen MS, Vanderwaerdt GD, Ewoldt LL, Cordes ME, Wigle DA, et al. Patient-centered quality indicators for pulmonary resection. Ann Thorac Surg. 2008;86:927-32.

10. Martin-Ucar AE, Medouye A, Deacon SE, Muhibullah N, Lau K, Bennett J, et al. Systematic evaluation of quality of care provided to patients undergoing pulmonary surgery helps to identify areas for improvement. Inter Cardiovasc Thorac Surg. 2010;10:394-8.

11. Cerfolio RJ, Bryant AS, Maniscalco LM. A nondivided intercostal muscle flap further reduces pain of thoracotomy: a prospective randomized trial. Ann Thorac Surg. 2008;85:1901-6.

12. Cerfolio RJ, Bryant AS, Patel B, Bartolucci AA. Intercostal muscle flap reduces the pain of thoracotomy: a prospective randomized trial. $J$ Thorac Cardiovasc Surg. 2005;130:987-93.

13. Cerfolio RJ, Price TN, Bryant AS, Sale Bass C, Bartolucci AA. Intracostal sutures decrease the pain of thoracotomy. Ann Thorac Surg. 2003;76:407-11. 
14. Cerfolio RJ, Bryant AS, Eloubeidi MA. Routine mediastinoscopy and esophageal ultrasound fine-needle aspiration in patients with non-small cell lung cancer who are clinically N2 negative: a prospective study. Chest. 2006;130:1791-5.

15. Cerfolio RJ, Bryant AS, Eloubeidi MA, Minnich DJ, Harbour KC, Dransfield MT. The true false negative rates of esophageal and endobronchial ultrasound in the staging of mediastinal lymph nodes in patients with non-small cell lung cancer. Ann Thorac Surg. 2010;90:427-34.

16. US Department of Health and Human Services. https://www.cms.gov/pqri/ (last accessed 9/8/10)

17. Society of Thoracic Surgeons Web site, http://www.sts.org/documents/pdf/ndb/ 1_-_Sample_Report_GT_Overview_-_88888.pdf (p. vii). (last accessed 6/7/10).

18. Centers for Medicare \& Medicaid Services http://www.cms.gov/PQRI/ 15_MeasuresCodes.asp\#TopOfPage (last accessed 9/7/10).

19. Copeland GP, Jones D, Walters M. POSSUM: a scoring system for surgical audit. Br J Surg. 1991;78:355-60.

20. Whiteley MS, Prytherch DR, Higgins B, Weaver PC, Prout WG. An evaluation of the POSSUM surgical scoring system. Br J Surg. 1996;83:812-5.

21. Borja-Cacho D, Parsons HM, Habermann EB, Rothenberger DA, Henderson WG, Al-Refaie WB. Assessment of ACS NSQIP's predictive ability for adverse events after major cancer surgery. Ann Surg Oncol. 2010;17:2274-82.

\section{Discussion}

Dr John R. Handy (Portland, Ore). I thank the Association for the invitation to make some comments and to pose some questions. Dr Cerfolio, your prodigious work effort always impresses a room full of people who dedicate their lives to prodigious work efforts, and this particular project is a tour de force in database detail and the actual gathering of data. I do not know how you and Dr Bryant actually pulled it off. It is the source of a fascinating mystery to me.

When I look at these types of efforts, I find it instructive to view them through the lens of the Donabedian formula for health care quality as defined by the structure in which the care is rendered, the processes of the care, and the outcomes. There is often a blurring of the terminology when discussing quality or its components.

Finally, I wonder whether you have not undersold your conclusions in that one very viable conclusion that you could have from your same data is that optimal care decreased morbidity. This is important because morbidity not only has human suffering but also has cost implications and, frankly, in high-quality programs, we probably have more opportunity for decreasing morbidity than mortality.

I have 3 questions, the first of which you already mentioned. My first question concerns the identification of your benchmarks, especially your critical versus your noncritical benchmarks, especially vis-à-vis things for which there are very few data, such as accomplishing a lobectomy in less than an hour and 40 minutes or a blood loss of less than $100 \mathrm{~mL}$. You are in a lonely position in this nascent field and your efforts are to be commended, but this is not a field devoid of information. The National Surgery Quality Improvement Program (NSQUIP), the POSSEM score (Physiologic and Operative Severity Score for Enumeration of Morbidity and Mortality), and the Mayo Clinic, for example, in 2008 Annals of Thoracic Surgery using 9 senior clinicians, including nonsurgeons such as physician's assistants and nurses, came up with patient-centered quality indicators for pulmonary resection. Finally, last year in the European Journal of Cardio-Thoracic Surgery the Glenfield Hospital group published a similar-type effort. So can you defend your selection of these particular 55 criteria?

Dr Cerfolio. First, thank you for your kind comments. It is a great question and the truth is that I really cannot defend them.
Those were things that we believed as a team. As you said, there is some literature out there, but not very specific nor validated benchmarks, particularly this set of patients that we have. That is why I list this as one of the weaknesses of the study: our benchmarks are not validated either.

Dr Handy. Second, can we use your practice to draw conclusions for the greater thoracic surgery community at large? Your program leverages the widely described benefits for improving outcomes, including high clinical volume, multidisciplinary care, and specialized care. Those are really not debatable. If you do the math, you are doing over 250 pulmonary resections for cure annually. Boffa's report of the general thoracic surgery database in the 2008 Journal of Thoracic and Cardiovascular Surgery is contributed to only by board-certified general thoracic surgeons. We are performing a median of 31 pulmonary lobectomies a year. So you are doing good things, but you are also not doing some things that had been shown to be of benefit. In February 2010, our 3 major journals, the Journal of Thoracic and Cardiovascular Surgery, the Annals of Thoracic Surgery, and the European Journal of Cardio-Thoracic Surgery, showed that video-assisted (VATS) lobectomy had less perioperative morbidity, had improved 6-month functional outcomes, and also had the same oncologic benefit at 5 years, so VATS lobectomy is a hard thing not to perform when you are talking about quality of care.

Dr Cerfolio. I agree and those are excellent points. After going to meeting after meeting, I would be dishonest scientifically if I did not say that I now believe that minimally invasive lobectomy, which can be done with VATS, may decrease morbidity. However, it is the improved 5-year survival of several reports that really got me interested in revisiting the concept of VATS, and after doing several more I started doing robotic lobectomies. We have done 46 completely portal robotic lobectomies now. It has changed my life in some way for the worse-home later-but it has been better for my patients in many ways. I have seen decreased morbidity doing minimally invasive robotic lobectomy. I am still not a big fan of VATS for many reasons. I still see a lot of pain from camera torquing on the intercostal nerve, probably because I have medical students most commonly driving my camera. I run several rooms and have a different medical student in each room who runs the camera, and as soon as they get good they are gone 2 weeks later. With robotic lobectomy, the surgeon drives the camera. With our technique, the surgeon provides the retraction using the robotic fourth arm, and the visibility, the lymph node dissection, and the vessel and N1 dissection are unequivocally easier to do with the robot than with VATS. It has been something that we are studying. I am a proponent of it, but I think we need to carefully study the increased cost and the time. However, we have seen decreased morbidity with it. It is a good point.

Dr Handy. Third, you accomplished your critical benchmarks and decreased morbidity. What exactly is the linkage for that?

Dr Cerfolio. That is another great question. The real question is, are the critical benchmarks nothing more than surrogates for patients doing well, as I tried to allude to in the presentation? If one benchmark is that the patients go home in 4 days, and then if they do not hit that benchmark and it is critical, then obviously there was a problem. In a way they are surrogates for patients doing well, but I think there is a little bit more to it than just that. As you say, this is an extremely complicated study where there are so much data that we are not sure if we have completely analyzed all of it all 
correctly. I look forward to the reviewers beating it up a little bit and chewing this out a little bit to help us make it better.

Dr Richard Whyte (Stanford, Calif). I applaud you on a great presentation and for your continued self-examination. I have a comment and a couple of questions.

First of all, I think that your final statement that "pay for performance is unsupported" is carefully chosen wording and, perhaps, better than calling it "unsupportable." I think that was intentional. Well done.

Dr Cerfolio. Right.

Dr Whyte. I think part of that may be because quality is not just short-term mortality, but also long-term mortality, length of stay, cost, and, as Scott Millikan pointed out so poignantly, relationships with the patient and his or her family. When you focus on just one area of quality, short-term mortality, I think that you miss some of the aspects of quality that are so important.

I have a couple of questions. First, maybe I misunderstood things, but in your presentation you pointed out that missing major benchmarks did not affect mortality.

Dr Cerfolio. It did not. The lack of delivery of the 10 critical benchmarks did not negatively affect operative mortality, but it was associated with increased major morbidity.

Dr Whyte. Okay, I was not sure. In the abstract it seemed to be different.

Dr Cerfolio. Things have changed since the abstract was submitted because we have done so many more statistical analyses. I cannot tell you what a pain in the neck this one has been, but we have done a million analyses since the abstract, so some messages have changed for sure.

Dr Whyte. Last, the educational component to this: you said $97 \%$ of the time you made all your intraoperative benchmarks. Now one of those on your list was the surgeon performing the skin incision.

Dr Cerfolio. Yes.

Dr Whyte. How do you teach the residents, particularly when you have chief residents, if $98 \%$ of the time you are doing the operation from skin to skin?

Dr Cerfolio. You have misinterpreted me making the incision versus me doing the whole case. I make the skin incision and then I give them the Bovie instrument and have them go from there. However, the point is I am there the entire time. I tell the patients who come to me that I am there. I make the skin incision. I am there for all the critical parts and really for the entire procedure, and I hold my word to the patients. But then I usually give the resident or the fellow the Bovie instrument as soon as I make the incision.

Dr Whyte. Interesting distinction.

Dr Cerfolio. No, I do. I make the skin incision and I am there when the skin is closed; I am there essentially the whole time. I may leave to do a rigid bronchoscopic procedure or a mediastinoscopy in the middle of a robotic lobe, and I tell them that; we leave a little extra time and use an hour and 40 minutes in there because I leave sometimes, but I am there when the operating is being done and for the opening and closing.

Dr Whyte. So are you serious that a major quality index is that you, personally, make a skin incision and then hand the Bovie instrument to someone else to do a lot of the operation?

Dr Cerfolio. Yes. I am aware of some places where there is some ghost surgery going on, and I know at least when I was doing it, mistakes resulting from inexperience were made. I think if you have a senior person there taking a resident or a fellow through the procedure, it is safer than the younger resident by himself. If the resident or fellow does it by himself or herself, depending on the level of experience, I think the quality of the product goes down.

Dr Whyte. I would agree with that. Thank you.

Dr Paul Schipper (Portland, Ore). I had a comment and a question. Now I have 2 questions.

When I read through your critical benchmarks in the published abstract, I noticed all of them with one exception were things that happened to you-as you said, surrogates for problems that occurred. The patient goes to the ICU, bleeding, transfusion. The only one that you could affect was whether or not they got pulmonary rehabilitation before the operation. In the new revised list of critical benchmarks, which of them can we do or affect and expect a better outcome?

Dr Cerfolio. It really gets tricky because if you talk to Ayesha Bryant, my partner and statistician, we can only allow patients who were eligible for a benchmark to be considered whether they got it. In other words, smoking cessation was a benchmark, but if the patient did not smoke, he or she was not eligible to get that particular benchmark. It gets very tricky when you look at what benchmarks you have delivered, because you do not want to penalize yourself for not delivering a benchmark that a particular patient was not even eligible for. We selected cardiopulmonary rehabilitation for selected patients, so the majority of patients who were supposed to get it were supposed to get it for a month. However, that was the lowest benchmark we delivered, because too often the patient is at home watching ESPN using the television remote control sitting in a recliner. He or she was not really doing the cardiopulmonary rehabilitation. Some of these things go on to the patient and patient factors.

Dr Schipper. This study shows your attention to detail and your ability to be self-critical, but I disagree somewhat with your conclusion about pay for performance.

Dr Cerfolio. It is easy for us to be self-critical, but go ahead.

Dr Schipper. The nationwide mortality for lobectomy is somewhere between $5 \%$ and $7 \%$, and yours is about half of that. What this study really represents is Team Rob Cerfolio doing all the things that you think you ought to do versus Team Rob Cerfolio when you stumble. Even when you stumble your outcome is better than that national average, so why not advocate pay for performance? You would probably get paid.

Dr Cerfolio. Well, I appreciate your saying that, but I am going to challenge you on that. We all know that there are many series out there, some from those in this audience, that show operative mortality less than $2 \%$. I have never been able to achieve that and I have been doing this for 14 years. I am very disappointed about that. There are a lot of very good surgeons in this room who have big series with mortalities of $1.8 \%$ and $1.7 \%$. I think with our robotic lobectomies we may get there.

Dr Schipper. But these are from the STS database and series out of Memorial Sloan Kettering. They are the cream of the crop, not the true national average.

Dr Cerfolio. You are right, but I think the minimally invasive technique, as much as I have been a very loud voice against it, may be able to decrease some of the mortality and the morbidity. Some of it is patient selection, but some of it is some of these other 
factors we have talked about, so we are going to see. We are halfway to 100 robotic lobectomies, and we will see where we are. So far, we have had no mortalities and the morbidity has been less.

Dr Scott Rankin (Nashville, Tenn). Congratulations on a very interesting approach. I would like to make one small methodologic comment about this paper and also Dr Grossi's paper. A principle of biostatistics is that 10 events should be available for every variable tested in a multivariable analysis. Without that, we have the potential for over-fitting. I am concerned that with the small number of events, testing so many variables represents over-fitting in the multivariable analysis.

Dr Cerfolio. That is a very good point. Dr Bryant and I have talked about that very fact as well. You asked whether it is a mys- tery how we do these. Well, it is not a mystery. We have constant communication. Many times she hates me and sometimes I get tired of her because we are always talking about our studies every single day.

I do want to make 1 last comment. I was talking about quality of care and patient satisfaction. We heard earlier today from our president that "hope is the currency of the waiting room." I think he is exactly right. We need more benchmarks that look at patient and family satisfaction, not just surgical intraoperative benchmarks. That is why I have so many of these in this paper. We may even need more, because that is really how we are measured, not just our outcomes but what the family perceives of the product we have delivered, even when the end result is not the one we were praying for preoperatively.

Patient Demographic Survey

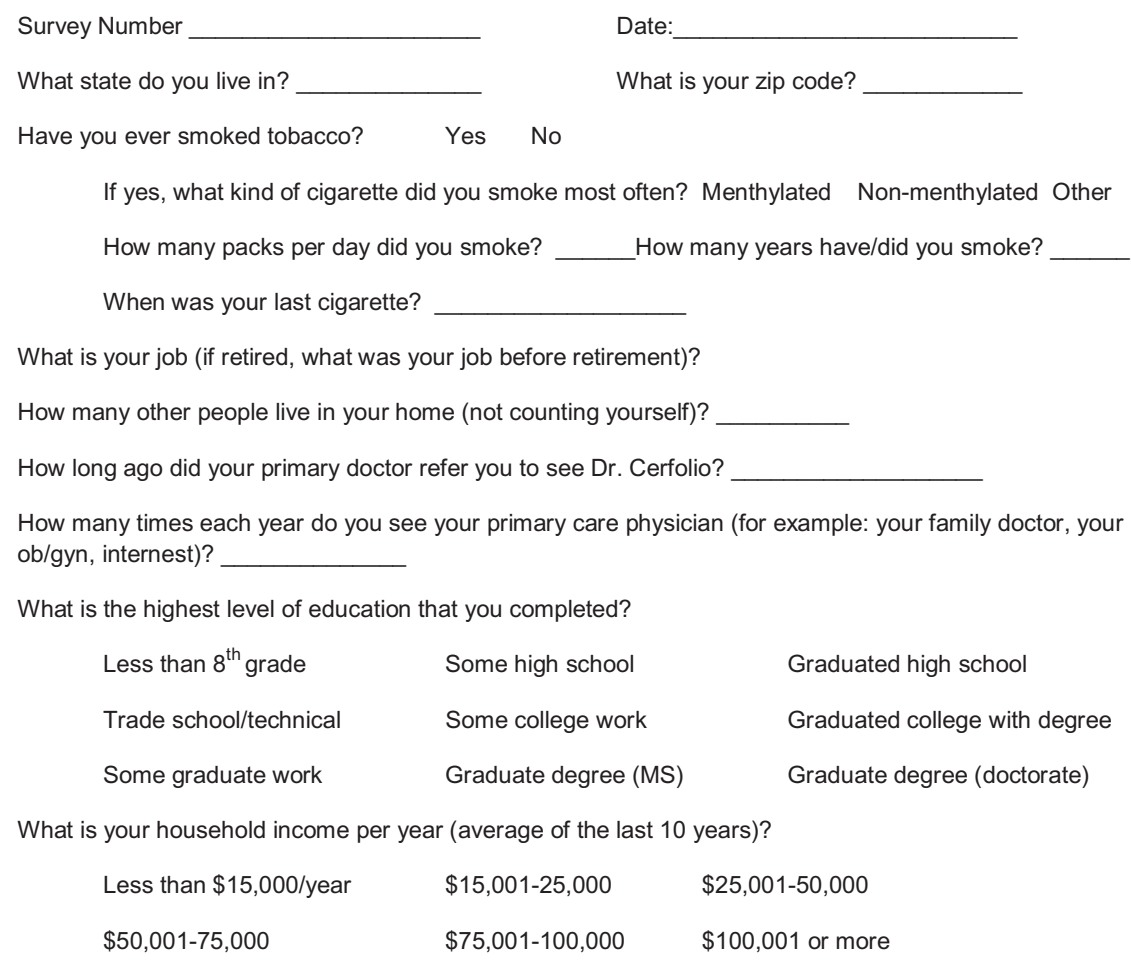

APPENDIX 1. Survey given in clinic to patients 